\title{
Evaluation of Corneal Endothelium Function by Combined Measurement of Corneal Volume and Specular Microscopy after Phacoemulsification
}

\section{'Mohammed Abd El basset Elwerdany ${ }^{1, *}$ MSc., Abd Allah El hoseiny shelil ${ }^{1}$ MD. and Omar Hassan Salama ${ }^{1}$ MD}

\author{
* Corresponding Author: \\ Mohammed Abd El basset \\ Elwerdany \\ elwerdany190@gmail.com
}

Received for publication
September 20, 2020; Accepted
November 7, 2020; Published online November 7, 2020.

\section{Copyright 2020 The Authors published by Al-Azhar University, Faculty of Medicine, Cairo, Egypt. All rights reserved. This an open-access article distributed under the legal terms, where it is permissible to download and share the work provided it is properly cited. The work cannot be changed in any way or used commercially. \\ doi: $10.21608 /$ aimj.2020.42585.1320 \\ ${ }^{1}$ Ophthalmology Department, \\ Faculty of Medicine, Al-Azhar \\ University, Cairo, Egypt.}

\section{ABSTRACT}

Background: Clarity of the cornea is fundamental for pure vision following cataract surgery including phacoemulsification . The pumping action of corneal endothelial cells acts to maintain this clarity through maintaining the corneal stroma dehydrated, so integrity of this cell layer function is very important for corneal clarity.

Aim of work: To evaluate endothelial cell layer function before and after phacoemulsification by assessment of changes in density of endothelial cell and corneal volume of central corneal ring of $10 \mathrm{~mm}$ diameter.

Patient and methods: A prospective interventional study was performed during the period from September2019 to December 2019 at Sayed Galal University Hospital. A total of 22 eyes from 15 subjects, aged $50-65$ years old, both genders were involved. All patients had an uneventful phacoemulsification for immature senile cataract. Patients were evaluated pre and postoperatively by Topcon ${ }^{\circledR}$ SP-1P specular microscope for cell density and by SIRIUS $® 3$ D rotating Scheimpflug \&amp; topography system for corneal volume of central $10 \mathrm{~mm}$ ring Results: Our results demonstrated that specular endothelial cell density decreased significantly and Central corneal volume increased significantly after phacoemulsification. Cell density changes Showed a reverse proportional correlation with corneal volume changes.

Conclusion: The increase in corneal volume following phacoemulsification can indicate the degree of the endothelial damage. A single anatomical or functional test may not be sufficient for definite evaluation of endothelial dysfunction after phacoemulsification.

Keywords: Corneal Endothelium Function; Corneal Volume; Specular Microscopy; Phacoemulsification.

Disclosure: The authors have no financial interest to declare in relation to the content of this article. The Article Processing Charge was paid for by the authors.

Authorship: All authors have a substantial contribution to the article.

\section{INTRODUCTION}

Dysfunction of endothelial cell layer of the cornea results in decompensation of the cornea with ultimate loss of vision. That is why , morphological as well as numerical stability in addition to functional integrity of corneal endothelium are fundamental for maintenance of corneal clarity following cataract surgery on the long term. ${ }^{1}$

Damage of the corneal endothelium in phacoemulsification procedure may occur in different ways. It may be injured mechanically as a result of anterior chamber instrumentation: chopper, phaco tip, irrigation/aspiration canula and/or anterior chamber manipulation of hard lens nucleus, ultrasonic vibration of the phaco tip, prolonged intraocular irrigation and heat generation. ${ }^{2}$

Specular microscopy is used for non-invasive viewing and recording of the image of the corneal endothelial cell layer. The laboratory microscope designed by Maurice represents the basis of all the clinical specular microscopes . ${ }^{3,4}$

Several studies have used specular microscopy for quantitative assessment of the corneal damage associated with phacoemulsification by measuring the degree of decrease in the central corneal cell density. However, the small measurement area in specular microscopy may not be a suitable method for evaluation of damage to the whole cornea.$^{5}$

Corneal endothelial status evaluation is clinically important. However, only the denisty and morphological changes of the endothelial cells are shown by specular microscopy and they do not necessarily reflect the actual status of the cells function; hence the need for other methods for evaluation of the corneal endothelium functions . Many trials have been made to evaluate the actual functions of corneal endothelium. ${ }^{6,7}$ 
Pentacam camera allows 3-dimensional analysis of the anterior segment of the eye. Software of Pachymetry in the Pentacam provides a color map of corneal thickness as well as calculation of the corneal volume within a $3.0,5.0,7.0$, or $10.0 \mathrm{~mm}$ central corneal ring. The corneal volume can reflect the actual endothelial cell function in the area owing to the fact that the barrier and pump functions of the endothelial cell layer acts to maintain dehydration status of the cornea. ${ }^{5}$

The aim of the work was to evaluate endothelial dysfunction after phacoemulsification by assessment of alterations in endothelial cell density by specular microscopy and central corneal volume of central corneal ring of $10 \mathrm{~mm}$ diameter.

\section{SUBJECTS AND METHODS}

Subjects:

A prospective interventional study was performed during the period from September 2019 to December 2019. A total of 22 eyes, from 15 subjects, aged 50 65 years old, both genders were involved and all eyes had immature senile cataract. Examination of all cases, surgery and follow- up was performed at Sayed Galal University Hospital.

A complete ophthalmic history and ophthalmological examination were done for each subject that comprised: Uncorrected visual acuity (UCVA) and Best corrected visual acuity (BCVA)using Snellen chart; Anterior segment detailed Slit Lamp examination (keeler 25z); Intraocular pressure measurement by applanation tonometer (keeler KAT$\mathrm{T}$ type); Posterior segment examination using Indirect ophthalmoscopy (Keeler- All Pupil II).

\section{Methods:}

Measurements of cell density by specular microscopy and corneal volume were done preoperatively and 1 month postoperatively.

Specular microscopy:

A non-contact specular microscope (Topcon SP1-P, Tokyo, Japan) was used to assess the central corneal endothelium and measurements were taken by a single examiner. The procedure for specular microscopy was as follows: Panorama mode 3 images from the central cornea were captured then the machine combines the 3 images giving awide analysis about the central corneal endothelium.

Corneal volume measurement:

The instrument used for computerized tomography was SIRIUS ${ }^{\circledR}$ 3D rotating Scheimpflug\& topography system, with the operating system PHOENIX ${ }^{\circledR}$ Software-Suite. Patients were positioned correctly then fixated on the target. Patients were asked to blink many times prior to image acquisition. Images with poor quality of acquisition were repeated to get a reliable measurement. Three reliable measurements were obtained each time and the mean corneal volume was used in all calculations.

\section{Surgical Procedures:}

Dilatation of eyes were done using phenylephrine $\mathrm{HCl} 2.5 \%$ eye drops and tropicamide $1 \%$ eye drops before surgery. All cataract surgeries were performed by One surgeon under local anesthesia. Asuperior incision of $2.8 \mathrm{~mm}$ was done in the clear cornea, followed by filling anterior chamber with viscoelastic (Optiflex ${ }^{\circledR}$ Sodium Hyaluronate $1.4 \%$, Moss Vision Inc. Ltd). After capsulorrhexis of about $6.0 \mathrm{~mm}$, phacoemulsification was done (INFINITI ${ }^{\circledR}$ vision system; Alcon, Novartis). A monofocal, foldable, hydrophilic, acrylic, biconvex IOL (OculoFlex®, Eye Pharma) was implanted in the bag. Corneal wound was then hydrated. Operation time was less than 18 minutes, with effective phaco time range 0.5 - 4.0 seconds in all patients; an example of phaco parameters is shown. Patients were then treated withantibiotic (Gatifloxacin 0.3\%) for 2 weeks and steroid (Prednisolone acetate 1\%) eye drops q.i.d for 4 weeks.

Inclusion criteria: Adult patients aging from 50 to 65 years with immature senile cataract, Both genders will be included.

Exclusion criteria:

We excluded any subject with any type of corneal dystrophy, glaucoma, and history of previous contact lens wear, ocular trauma, ocular disease/surgery or systemic diseases known to affect corneal endothelium. Patients with preoperative CD of less than 1500 cell $/ \mathrm{mm}^{2}$, intra operative complications i.e., posterior capsule rupture, vitreous prolapse, iris prolapse were excluded. Patients with postoperative complications i. e., increased IOP, were also excluded. Patients who were not able to maintain follow up period of 1 month were also excluded.

Ethical considerations:

Our study was performed following Medical Research Ethical Committee principles at Al-Azhar University as well as the Helsinki Declaration. Informed consents were obtained from patients following guarantee of data confidentiality.

\section{Data management and statistical analysis}

Data were collected, coded, revised, tabulated and analyzed using the Statistical Package for Social Science (IBM SPSS) version 20. Qualititative data were presented as number and percentages ;quantitative data with parametric distribution were presented as mean, standard deviations and ranges and quantitative data with non-parametric distribution were presented as median with inter quartile range (IQR) .The comparison between two groups with quantitative data for before and after and parametric distribution was performed using paired $\mathrm{T}$ test . Meanwhile, two groups with quantitative data for before and after and non-parametric distribution were compared using Wilxon Rank test. Spearman correlation coefficients were used for assessment of significant correlation between two quantitative parameters in the same group. 


\section{RESULTS}

The study included 22 cataractous eyes, from 15 subjects, 4 males and 11 females, aged 50 - 65 years old. Operated eyes were 10 right and 12 left. Demographic data of included patients are shown in table 1 .

\begin{tabular}{|c|c|c|c|}
\hline \multicolumn{2}{|c|}{} & Range & Mean \pm SD \\
\hline \multicolumn{2}{|c|}{ Age (years) } & $50-65$ & $57.95 \pm 5.56$ \\
\hline \multirow{2}{*}{ Gender } & Male & No & $\%$ \\
\cline { 2 - 4 } & Female & 11 & $26.7 \%$ \\
\hline \multirow{2}{*}{ Laterality } & LT & 12 & $73.3 \%$ \\
\cline { 2 - 4 } & RT & 10 & $54.5 \%$ \\
\hline
\end{tabular}

Table 1: Demographic data distribution. SD: standard deviation, No: Number, LT: left, RT: right.

Mean preoperative cell density was 2954.41 with range from 2346 to $3831 \mathrm{cell} / \mathrm{mm}^{2}$. Mean postoperative cell density was decreased to 2500.18 with range from 1460 to 3231 cells $/ \mathrm{mm}^{2}$. A statistically significant $(\mathrm{p}<0.001)$ drop was observed in $\mathrm{CD}$, Table (2).

\begin{tabular}{|c|c|c|c|c|c|c|c|c|c|c|c|c|}
\hline & \multicolumn{3}{|c|}{ Pre } & \multicolumn{3}{|c|}{ Post } & \multicolumn{3}{|c|}{ Change (\%) } & \multicolumn{2}{|c|}{ Paired t- test } & \multirow[b]{2}{*}{ Significance } \\
\hline & Mean & SD & Range & Mean & SD & Range & Mean & SD & Range & $\mathrm{t}$ & $\begin{array}{c}\mathrm{P}- \\
\text { value }\end{array}$ & \\
\hline $\begin{array}{c}\mathrm{CD} \\
\left(\mathrm{cell} / \mathrm{mm}^{2}\right)\end{array}$ & 2954.41 & 406.32 & $\begin{array}{c}2346- \\
3831\end{array}$ & 2559.27 & 457.54 & $\begin{array}{l}1681- \\
3231\end{array}$ & $\begin{array}{c}-395.14 \\
(13.28 \\
\%)\end{array}$ & 303.98 & $\begin{array}{c}-20- \\
)- \\
1071)\end{array}$ & 4.236 & $\stackrel{<}{0.001}$ & HS \\
\hline $\begin{array}{l}\text { Corneal } \\
\text { volume } \\
\left(\mathrm{mm}^{3}\right)\end{array}$ & 56.70 & 2.62 & $\begin{array}{c}49.2- \\
62.8\end{array}$ & 59.27 & 3.12 & $\begin{array}{l}53- \\
67.9\end{array}$ & $\begin{array}{c}2.58 \\
(4.55 \%)\end{array}$ & 1.72 & $\begin{array}{l}6.3- \\
0.10\end{array}$ & $\begin{array}{c}- \\
7.032\end{array}$ & $\begin{array}{c}< \\
0.001\end{array}$ & HS \\
\hline
\end{tabular}

Table 2: Cell Density values and Corneal volume values: preoperative, postoperative \& change. CD: cell density, SD: Standard deviation, Pre: preoperative, Post: postoperative, t: paired t- test value, HS: Highly significant.

Mean preoperative corneal volume was 56.70 $\mathrm{mm}^{3}$ with range from 49.2 to $62.8 \mathrm{~mm}^{3}$; mean postoperative corneal volume was decreased to 59.27 $\mathrm{mm}^{3}$ with range from 53 to $67.9 \mathrm{~mm}^{3}$. A statistically significant $(\mathrm{p}<0.001)$ increase was observed in postoperative corneal volume, Table (2).

\begin{tabular}{|c|c|c|c|c|c|c|c|c|c|c|c|c|}
\hline & \multicolumn{3}{|c|}{ Pre } & \multicolumn{3}{|c|}{ Post } & \multicolumn{3}{|c|}{ Change (\%) } & \multicolumn{2}{|c|}{$\begin{array}{c}\text { Wilxon Rank } \\
\text { test }\end{array}$} & \multirow{2}{*}{ Significance } \\
\hline & Median & IQR & Range & Median & IQR & Range & Median & IQR & Range & $\mathrm{R}$ & $\begin{array}{c}\mathrm{P}- \\
\text { value }\end{array}$ & \\
\hline BCVA & 0.1 & $\begin{array}{c}(0.05- \\
0.2)\end{array}$ & $\begin{array}{c}0.01- \\
0.70\end{array}$ & 0.4 & $\begin{array}{c}0.2- \\
0.7\end{array}$ & $\begin{array}{c}0.02- \\
0.80\end{array}$ & $\begin{array}{c}0.3 \\
(300 \%)\end{array}$ & $\begin{array}{c}0.10- \\
0.50\end{array}$ & $\begin{array}{c}-0.5- \\
0.7\end{array}$ & 3.559 & 0.001 & HS \\
\hline
\end{tabular}

Table 3: BCVA: preoperative, postoperative \& change. BCVA: best corrected visual acuity, IQR : inter quartile range , HS: Highly significant.

BCVA improved in all operated eyes. Median preoperative BCVA was 0.1 as it ranged from 0.01 to 0.70 , median postoperative $\mathrm{BCVA}$ was 0.4 with range from 0.02 to 0.80 . A statistically significant $(\mathrm{P}=$ $0.001)$ increase in BCVA occurred postoperatively , Table (3).

\begin{tabular}{|c|c|c|}
\hline \multirow{2}{*}{} & \multicolumn{2}{|c|}{ Cell density change } \\
\cline { 2 - 3 } & $\mathrm{R}$ & $\mathrm{p}$ value \\
\hline $\begin{array}{c}\text { Corneal volume } \\
\text { change }\end{array}$ & -0.771 & 0.001 \\
\hline
\end{tabular}

Table 4: Correlation between cell density changes and corneal volume changes. r: Spearman correlation test value.

Changes in $\mathrm{CD}$ were tested for correlation to changes in corneal volume. Results showed that cell density change has reverse proportional correlation with corneal volume change as decrease in cell density post-operative lead to significant increase in corneal volume, Table (4).

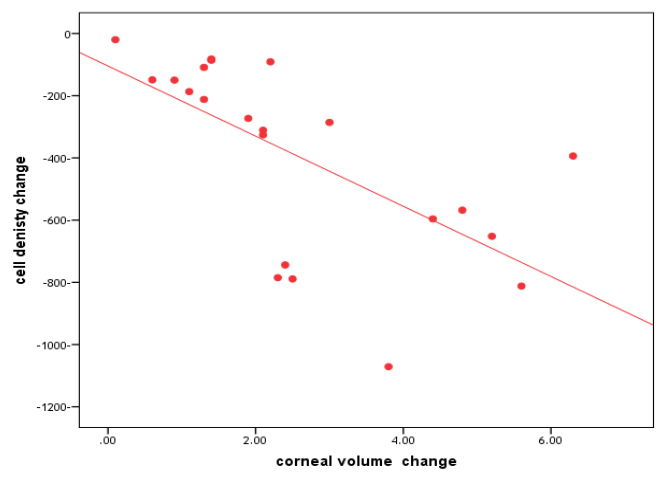

Figure 1: Correlation between cell density changes and corneal volume changes. 


\section{DISCUSSION}

Phacoemulsification has already shown as a minimally invasive surgical method, Nevertheless, endothelial compromise does occur after phacoemulsification as a result of traumatic stress on the cornea.$^{9}$ Corneal injury is still an important complication as phacoemulsification is performedeven in eyes with poor corneal endothelial reservoir or a hard lens nucleus.$^{10}$

Assessment of corneal endothelial cell morphology and density helps to provide vital information concerning corneal endothelial viability and function. Furthermore, itis an acceptance factor in practice and research through providing valuable information on this layer. ${ }^{11}$ Alterations in Endothelial mosaic are considered essential indicators of surgical trauma and are important in estimation of the safety of different surgical techniques. ${ }^{8}$

Despite importance of these measurements, but it remains an anatomical not functional evaluation. Furthermore, measurements cover a very small area in the central cornea and do not represent the entire cornea. So, functional evaluation methods were suggested.

Assessment of corneal thickness is also limited to the area of pacymetry and has the same limitations of specular microscopy, despite being a functional test. Fluorophotometry is an invasive technique and is a complex procedure to be done in common practice. So, none of these procedures alone can be considered the ideal for evaluation of corneal endothelial function.

Scheimpflug cameras allow a more detailed study of the anterior segment. Suzuki et al. ${ }^{5}$ introduced an assay of corneal volume using Pentacam ${ }^{\circledR}$ (Scheimpflug based instrument) as a possible new method for assessment of corneal endothelial damageresulting from phacoemulsification. In our work, we have used Sirius ${ }^{\circledR}$ 3D Rotating Scheimpflug Camera \& Topography System, a readily available device at our institution.

Investigators compared different Scheimpflug based instruments for anterior segment imaging. BaradaranRafii et al. ${ }^{12}$ used two Scheimpflug camera machines; Galilei ${ }^{\circledR}$ and Pentacam ${ }^{\circledR}$ to measure and compare anterior segment indices. Analyzed parameters includedaxial curvature, anterior and posterior best fit spheres (BFS), central corneal thickness (CCT), true corneal power, pupil diameter, anterior chamber (AC) depth, AC angle and AC volume. They found that there was a significant correlation between the Pentacam ${ }^{\circledR}$ and Galilei ${ }^{\circledR}$ in all measured parameters apart fromaverage pupil diameter, $\mathrm{AC}$ volume and AC angle.

Anayol et al. ${ }^{13}$ compared the central corneal thickness and the thinnest corneal measurement among Galilei ${ }^{\circledR}$, Pentacam ${ }^{\circledR}$ and Sirius ${ }^{\circledR}$ devices and observed that interchangeable use of pachymetry measurements obtained by different devices is not possible. They found that the measurements by the Galilei® were significantly higher when compared with those obtained by either the Pentacam ${ }^{\circledR}$ or the Sirius ${ }^{\circledR}$ systems and showed that Pentacam ${ }^{\circledR}$ and Sirius ${ }^{\circledR}$ systems agreed better with each other than with the Galilei®. They added that, difference observed among different studies can be attributed to the various software versions used in each study.

Kirchhoff et al. ${ }^{9}$ measured 3-mm corneal volume changes after cataract surgery with Orbscan and reported that corneal volume increased at six hours post-operative, and did not return to preoperative levels by 24 hours post-operative . Short term central changes were then confirmed by Suzuki et al. ${ }^{5}$ where the increased corneal volume that noticed early within the first week in the 3-mm diameter area, almost returned to the preoperative values at 1 month follow up. On the other hand, corneal volumes of $10 \mathrm{~mm}$ central rings at one month were still significantly higher when compared with the preoperative volmes.

Studies on corneal volume changes agree with previous studies on corneal pachymetric changes. Ravalico et al. 8 reported that postphacoemulsification central corneal thickness returned to preoperative levels within one month post-operative . Another report by Doganay et al. ${ }^{14}$ revealed that endothelial changes occur due to mechanical as well as traumatic stress during phacoemulsification. Furthermore, previous reports of increased corneal thickness following phacoemulsification have described a variable postoperative increase in thickness and were associated with loss of endothelial cell, with most corneas returning to normal thickness by 1 month.

Based on these reports, we have chosen to measure the long lasting corneal volume changes at 1 month postoperatively over a wide diameter $(10 \mathrm{~mm})$ area to test for widespread endothelial dysfunction following phacoemulsification. Follow up period of 1 month durationmay be sufficient for subsidenceof surgeryinduced thermal or mechanical stromal injury. Moreover,cases with epithelial edema(i. e., increased IOP) after surgery were excluded from the study. So, in our study, the persistently increased corneal volume at 1 moth after surgery should be solely due to endothelial dysfunction.

Through literature review, factors that affect the corneal endothelial cell density and morphology may include: corneal disease, glaucoma, pseudoexfoliation, history of trauma age, race, ocular surgeries (cataract, refractive) ${ }^{15}$, Type 2 Diabetes Mellitus ${ }^{16}$, Years of contact lens wear ${ }^{11}$ and phakic intraocular lens implantation. ${ }^{17}$

Patients with ocular surgery, ocular or systemic disease known to affect corneal endothelium were excluded from the study. We excluded patients with preoperative CD less than 1500 cell $/ \mathrm{mm}^{2}$, such 
patients may be inappropriate candidates for phacoemulsification surgery. We also excluded patients with intra operative or postoperative complications that may compromise corneal endothelium.

The major outcome parameters in our study included changes in: mean endothelial cell density $(\mathrm{CD})$ and mean corneal volume.

Our measurements showed that the mean $\mathrm{CD}$ decreased by about $13.28 \%$, drop in $\mathrm{CD}$ was statistically significant $(\mathrm{p}<0.001)$, Table (4).

Ravalico et al. ${ }^{8}$ reported that the percentage of cell loss was $10.1 \%$ in the ECCE group and $8.5 \%$ in the phacoemulsification group at 30 days post-operative Suzuki et al. ${ }^{5}$ reported that the central CD decreased for each of the 3 participating surgeons,differences between surgeons were insignificant. Through their diagrams, decreased CD ranged from $4 \%$ to $11 \%$. We noticed that, the third surgeon, who has the least $\mathrm{CD}$ drop, used ophthalmic visco surgical device Healon5 in comparison to Healon and Viscoat used by other surgeons. He also used the least instrument parameters settings in comparison to other surgeons. Despite differences in CD drop between surgeons were statistically insignificant, but unifying surgical details may be important to decrease bias.

Regarding corneal volume changes in our study, we reported an average increase in corneal volume of $2.58 \mathrm{~mm}^{3}(4.55 \%)$ at 1 month postoperatively, a result that was highly significant statistically $(\mathrm{p}<0.001)$

Results reported by other authors varied according to the postoperative period at time of measurement. Kirchhoff et al. ${ }^{9}$ reported a significant $(\mathrm{p}<0.001)$ increase in the corneal volume (15.5\%) 6 hours after phacoemulsification. An average drop of $5.05 \mathrm{~mm} 3$ $(6.01 \%)$ then happened within 24 hours (values returned to almost half between pre operativeand 6 hours postoperative values), volume drop was also significant $(\mathrm{p}<0.001)$. Increased corneal volume was slightly higher than increased corneal thickness that increased postoperatively by $13.9 \%$ that then decreased within 24 hagain by $6.6 \%$. In their work, Suzuki et al. ${ }^{5}$ reported results of increased corneal volume 1 month afte rphacoemulsification. Through their diagrams, the percentage of increased volume did not exceed 3\% for any of the 3 participated surgeons. A result that was close to our results.

When we compared changes in $\mathrm{CD}$ to changes in corneal volume, results showed that cell density change has reverse proportional correlation with corneal volume change as decrease in cell density postoperatively lead to significant increase in corneal volume $(\mathrm{P}=0.001)$

Relatively similar results were reported by Lundberg et al. $^{18}$, as they found a strong correlation between the central corneal swelling at day 1 postoperative and the central corneal endothelial cell loss at 3 months. Rather than the corneal volume, they measured the central corneal thickness using both ultrasound pachymetry and Orbscan II. They concluded that measurement of the difference in pachymetry at day 1 postoperative is a useful way for assessment of the effects induced by the phacoemulsification procedure on the corneal endothelium.

In contrary to our reported correlation, Suzuki et al. ${ }^{5}$ mentioned that increases recorded for the $10-\mathrm{mm}$ corneal volumes occurred similarly with included surgeons although a little decreasing rate for the central $C D$ was noticed with the third surgeon. The correlation between these two parameters was analyzed among all subjects, but no statistically significant correlations were found.

Later on, Suzuki et al. ${ }^{10}$ introduced the VSI and concluded that it can be helpful in assessment of the corneal endothelium functions following phacoemulsification. In their study, an immediate post-operative increase in the VSI with slow decreasing as time passed, suggesting significant changes in the the residual corneal endothelium function following phacoemulsification until it reaches a constant level.

These findings support a previous report by Ravalico et al. ${ }^{8}$ who used Anterior segment fluorophotometry, endothelial specular microscopy and ultrasonic pachymetry for evaluation of corneal endothelial function following cataract surgery . Their results indicated a significant increase in the endothelial pump function 7 days following phacoemulsification. Another support was the increased polymegathism and pleomorphism after cataract surgery that was supposed to be an anatomical and functional compensatory mechanism for decreased CD. ${ }^{19}$

The software of the instrument used in our work (Sirius ${ }^{\circledR}$ ) permits measurement of the corneal volume over $10 \mathrm{~mm}$ diameter area. So, evaluation of the VSI was beyond our study, as the calculation of Volume Stress Index was performed using the central $\mathrm{CD}$ value combined with the value of $3.0 \mathrm{~mm}$ corneal volume. Moreover, the described method of calculating the SVI has supposed that the CD of the central $1 \mathrm{~mm}^{2}$, as measured by available specular microscopes, is representative of $\mathrm{CD}$ over the central area of $3 \mathrm{~mm}$ diameter $\left(>7.0 \mathrm{~mm}^{2}\right)$, such point of criticism for VSI is considerable.

\section{CONCLUSION}

The corneal volume increase in central corneal ring of $10 \mathrm{~mm}$ after phacoemulsification procedure can be agood indicator of the degree of the endothelial damage in the area so corneal volume evaluation is very important for accurate endothelial function evaluation and combined evaluation with specular microscopy and corneal volume is more beneficial and accurate than specular microscopy alone.

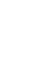




\section{REFERENCES}

1. Ventura ACS, Walti R and Bohnke $\mathrm{M}$. Corneal thickness and endothelial density before and after cataract surgery. $\mathrm{Br} \quad J$ Ophthalmol 2001; 85:18-20.

2. Miyata $\mathrm{K}$, Nagamoto $\mathrm{T}$, Maruoka $\mathrm{S}$, et al. Efficacy and safety of the soft-shell technique in cases with a hard lens nucleus. $J$ Cataract Refract Surg 2002; 28: 1546-50.

3. Edelhauser HF. The Balance between Corneal Transparency and Edema. Invest Ophthalmol Vis Sci. 2006; 47: 1755-67.

4. Benetz BA, Gal RL, Rubin LG, et al. Specular Microscopy Ancillary Study Methods for Donor Endothelial Cell Density Determination of Cornea Donor Study Images. Current Eye Research 2006; 31:319-27.

5. Suzuki H, Takahashi H, Hori $J$, et al. Phacoemulsification associated corneal damage evaluated by corneal volume. Am J Ophthalmol 2006; 142:525-8.

6. Inoue $\mathrm{K}$, Takuda $\mathrm{Y}$, Inoue $\mathrm{Y}$, et al. Corneal endothelial cell morphology in patient undergoing cataract surgery. Cornea 2002; 21(4): 360-3.

7. Arita R, Arita M, Kawai M, et al. Evaluation of corneal endothelial pump function with a cold stress test. Cornea 2005; 24: 571-5.

8. Ravalico G, Tognetto D, Palomba MA, et al. Corneal endothelial function after extracapsular cataract extraction and phacoemulsification. J Cataract Refract Surg 1997; 23: 1000-5.

9. Kirchhoff A, Böhm H, Schäferhoff C, et al. Messung des Hornhautvolumens Einmöglicher. Qualitätsparameter in der Kataraktchirurgie? [Corneal volume measurement. A possible quality parameter in cataract surgery?] Der Ophthalmologe 2001; 98: 402- 5 .

10. Suzuki H, Oki K, Takahashi K, et al. Functional evaluation of corneal endothelium by combined measurement of corneal volume alteration and cell density after phacoemulsification. J Cataract Refract Surg., 2007; 33: 2077-82.

11. Sheng $\mathrm{H}$ and Bullimore MA. Factors affecting corneal endothelial morphology. Cornea. 2007; 26(5): 520-5.

12. Baradaran-Rafii A, Motevasseli T, Yazdizadeh $\mathrm{F}$, et al. Comparison between Two Scheimpflug Anterior Segment Analyzers. $J$ Ophthalmic Vis Res 2017; 12(1): 2329.

13. Anayol M, Güler E, Yagci R, et al. Comparison of Central Corneal Thickness, Thinnest Corneal Thickness, Anterior Chamber Depth, and Simulated Keratometry Using Galilei, Pentacam, and Sirius Devices. Cornea 2014; 33: 582586.
14. Doganay S, Firat PB, Emre S, et al. Evaluation of anterior segment parameter changes using the Pentacam after uneventful phacoemulsification. ActaOphalmologica. 2010; 88(5): 601-6.

15. Kwon JW, Cho KJ, Kim HK, et al. Cornea: September 2016 - Volume 35 - Issue 9 - p 1206-10.

16. Rachapalle RS, Rajiv R and Tarun S. Changes in the Corneal Endothelial Cell Density and Morphology in Patients with Type 2 Diabetes Mellitus. 2012; 15: 147-53.

17. Moshirfar M, Imbornoni LM, Ostler EM, et al. Incidence rate and occurrence of visually significant cataract formation and corneal decompensation after implantation of Verisyse/Artisan phakic intraocular lens. Clin Ophthalmol. 2014; 8: 711-6.

18. Lundberg B, Jonsson $\mathrm{M}$ and Behndig A. Postoperative corneal swelling correlate strongly to corneal endothelial cell loss after phacoemulsification cataract surgery. Am J Ophthalmol 2005; 139: 1035-41.

19. Rio-Cristobal A and Martin R. Corneal assessment technologies: Current status. Surv Ophthalmol. 2014; 59: 599-614. 